\title{
JBIR-59, a new sorbicillinoid, from a marine-derived fungus Penicillium citrinum SpI080624G1f01
}

\author{
Jun-ya Ueda $^{1}$, Junko Hashimoto ${ }^{1}$, Shigeki Inaba ${ }^{2}$, Motoki Takagi ${ }^{1}$ and Kazuo Shin-ya ${ }^{3}$
}

The Journal of Antibiotics (2010) 63, 203-205; doi:10.1038/ja.2010.19; published online 5 March 2010

Keywords: Penicillium citrinum; radical scavenger; sorbicillin; sorbicillinol

The marine environment has recently been described as a source of novel chemical diversity for drug discovery, as many bioactive substances are isolated from marine organisms such as phytoplankton, algae, sponges, tunicates and mollusks. ${ }^{1,2}$ Microorganisms, especially fungi, from marine habitats also constitute a promising untapped resource of novel compounds and are receiving special attention. ${ }^{3-5}$ We have recently discovered novel compounds, namely sesquiterpenes JBIR-27 and JBIR-28, ${ }^{6}$ aspochracin derivative JBIR- $15^{7}$ and glycosyl benzenediols JBIR-37 and JBIR-38, ${ }^{8}$ from marine-derived fungi. Therefore, we attempted to isolate fungi from a marine sponge, Demospongiae, to obtain novel substances from the fungal culture. In the course of our screening program for discovering novel compounds from marine-derived fungi, we isolated a new compound termed JBIR-59 (1, Figure 1a) together with six known compounds, that is, redoxcitrinin, ${ }^{9}$ bisorbibutenolide, ${ }^{10}$ bisvertinolone, ${ }^{11}$ trichodimerol ${ }^{12}$ and sclerotinin $\mathrm{A}$ and $\mathrm{B},{ }^{13}$ from the mycelial extract of Penicillium citrinum SpI080624G1f01. We report herein the fermentation, isolation and, in brief, the biological activity of $\mathbf{1}$.

Penicillium citrinum SpI080624G1f01 was isolated from the marine sponge, Demospongiae, collected offshore of Ishigaki island, Okinawa Prefecture, Japan. SpI080624G1f01 was cultivated in $50 \mathrm{ml}$ test tubes containing $15 \mathrm{ml}$ of potato dextrose broth $\left(24 \mathrm{gl}^{-1}\right.$ potato dextrose; BD Biosciences, San Jose, CA, USA). The test tubes were shaken on a reciprocal shaker (355 r.p.m.) at $27^{\circ} \mathrm{C}$ for 3 days. Aliquots $(5 \mathrm{ml})$ of the culture were transferred to 500-ml Erlenmeyer flasks containing $15 \mathrm{~g}$ of brown rice (Hitomebore, Miyagi, Japan), $30 \mathrm{mg}$ of Bacto-yeast extract (BD Biosciences), $15 \mathrm{mg}$ of sodium tartrate, $15 \mathrm{mg}$ of potassium hydrogenphosphate and $45 \mathrm{ml}$ of water; further, the aliquots were incubated in static culture at $27^{\circ} \mathrm{C}$ for 14 days.

The mycelium (gathered from 10 flasks) was extracted with $80 \%$ aq. $\mathrm{Me}_{2} \mathrm{CO}$. After concentration in vacuo, the aqueous concentrate was extracted with EtOAc. The obtained organic layer was dried over anhydrous $\mathrm{Na}_{2} \mathrm{SO}_{4}$ and evaporated to dryness. The dried residue was washed with $n$-hexane- $\mathrm{CHCl}_{3}(6: 1)$, and its insoluble fraction was subjected to normal-phase medium-pressure liquid chromatography (Purif-Pack SI $60 \mu \mathrm{m}$, Moritex, Tokyo, Japan) and eluted with a stepwise solvent system of $\mathrm{CHCl}_{3}-\mathrm{MeOH}$ (100:0, 99:1, 98:2, 95:5, 90:10 and 50:50, successively). The $\mathrm{CHCl}_{3}$-eluate afforded redoxcitrinin, whereas the $\mathrm{CHCl}_{3}-\mathrm{MeOH}$ (99:1-98:2)-eluted fraction was chromatographed on reversed-phase medium-pressure liquid chromatography (Purif-Pack ODS $100 \mu \mathrm{m}$, Moritex) to yield bisorbibutenolide, bisvertinolone, trichodimerol and sclerotinin A and B. A portion $(20 \mathrm{mg})$ of the $\mathrm{CHCl}_{3}-\mathrm{MeOH}(98: 2)$-eluate $(134 \mathrm{mg})$ was purified by preparative reversed-phase HPLC using an XBridge Prep $\mathrm{C}_{18}$ column $(5.0 \mu \mathrm{m}$ OBD, 19 i.d. $\times 150 \mathrm{~mm}$; Waters, Milford, MA, USA) developed with $55 \% \mathrm{MeOH}-\mathrm{H}_{2} \mathrm{O}$ (flow rate: $10 \mathrm{ml} \mathrm{min}^{-1}$ ) to yield 1 ( $12.3 \mathrm{mg}$, retention time: $17.2 \mathrm{~min}$ ).

Compound 1 was obtained as a yellow amorphous solid $\left([\alpha]_{\mathrm{D}}^{27}\right.$ $-350^{\circ}$, c 0.1, in $\mathrm{MeOH}$; UV $\lambda_{\max } 221,263$ and $387 \mathrm{~nm}$, in $\mathrm{MeOH}$ ), and its molecular formula was determined to be $\mathrm{C}_{23} \mathrm{H}_{28} \mathrm{O}_{7}$ by HR-ESI-MS ( $m / z$ 417.1910, $(\mathrm{M}+\mathrm{H})^{+}$; calcd for $\left.\mathrm{C}_{23} \mathrm{H}_{29} \mathrm{O}_{7}, 417.1913\right)$. The IR spectra $\left(v_{\max } 1658 \mathrm{~cm}^{-1}\right)$ of 1 showed the presence of a conjugated ketone. The direct connectivity between each proton and carbon was established by the HSQC spectrum, and the ${ }^{13} \mathrm{C}$ and ${ }^{1} \mathrm{H}$ NMR spectral data for $\mathbf{1}$ are listed in Table 1. A planar structure was established by double-quantum filtered COSY spectrum together with constant time $\mathrm{HMBC}^{14}$ spectrum as follows.

An allylic coupling between the methyl protons $10-\mathrm{H}_{3}\left(\delta_{\mathrm{H}} 2.01\right)$ and an olefinic proton $2-\mathrm{H}\left(\delta_{\mathrm{H}} 5.64\right)$ was observed in the double-quantum filtered COSY spectrum, as shown in Figure $1 \mathrm{~b}$. In the $\mathrm{HMBC}$ spectrum, the ${ }^{1} \mathrm{H}-{ }^{13} \mathrm{C}$ long-range correlations from $2-\mathrm{H}$ to an olefinic carbon $\mathrm{C}-3\left(\delta_{\mathrm{C}} 161.6\right)$ and two quaternary carbons

\footnotetext{
${ }^{1}$ Biomedicinal Information Research Center (BIRC), Japan Biological Informatics Consortium (JBIC), Koto-ku, Tokyo, Japan; ${ }^{2}$ NITE Biotechnology Development Center (NBDC), Department of Biotechnology, National Institute of Technology and Evaluation (NITE), Kisarazu, Chiba, Japan and ${ }^{3}$ Biomedicinal Information Research Center (BIRC), National Institute of Advanced Industrial Science and Technology (AIST), Koto-ku, Tokyo, Japan

Correspondence: Dr K Shin-ya, Biomedicinal Information Research Centre (BIRC), National Institute of Advanced Industrial Science and Technology (AIST), 2-4-7 Aomi, Koto-ku, Tokyo 135-0064, Japan.

E-mail: k-shinya@aist.go.jp or Dr M Takagi, Biomedicinal Information Research Centre (BIRC), Japan Biological Informatics Consortium (JBIC), 2-4-7 Aomi, Koto-ku, Tokyo 135-0064, Japan.

E-mail: motoki-takagi@aist.go.jp

Received 7 December 2009; revised 16 February 2010; accepted 17 February 2010; published online 5 March 2010
} 

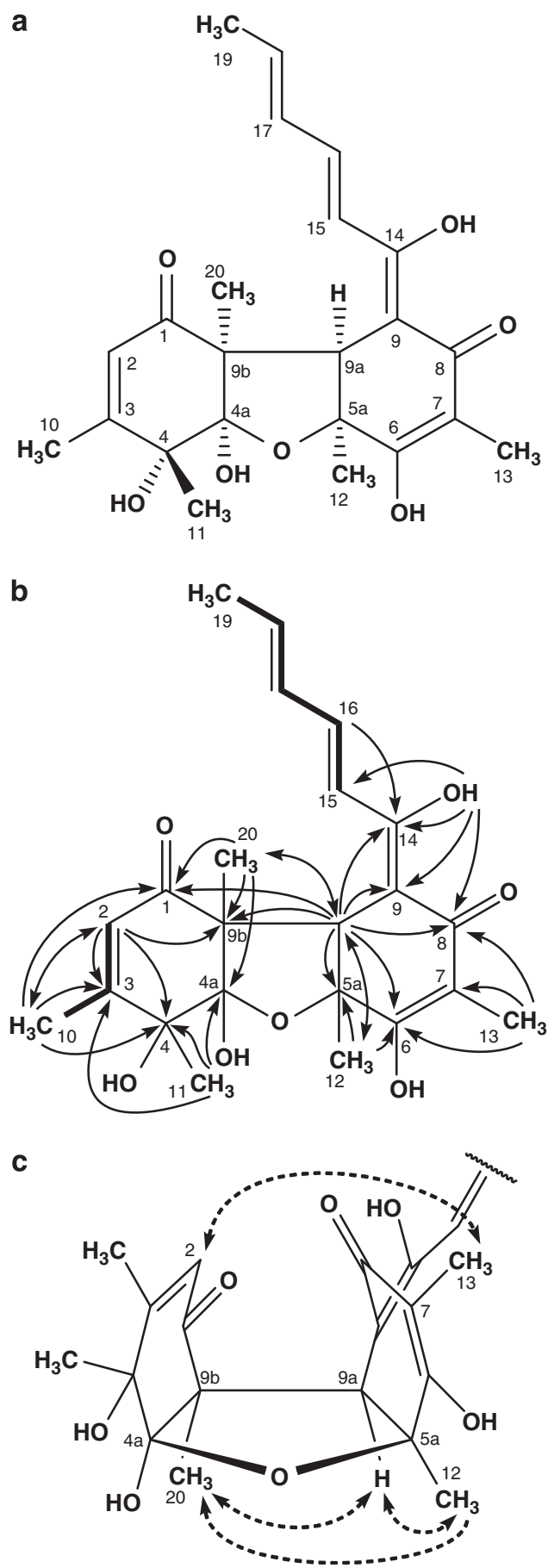

Figure 1 (a) Structure of 1 . (b) Key correlations of ${ }^{1} \mathrm{H}-{ }^{1} \mathrm{H}$ double-quantum filtered COSY (bold line) and HMBC (arrow, proton to carbon) of 1. (c) NOE observation for $\mathbf{1}$ (dashed arrow).

C-4 $\left(\delta_{\mathrm{C}} 76.9\right)$ and C-9b $\left(\delta_{\mathrm{C}} 59.6\right)$; from $10-\mathrm{H}_{3}$ to $\mathrm{C}-2\left(\delta_{\mathrm{C}} 125.6\right)$, $\mathrm{C}-3$ and C-4; from the methyl protons $11-\mathrm{H}_{3}\left(\delta_{\mathrm{H}} 1.36\right)$ to C-3, C-4 and an acetal carbon $\mathrm{C}-4 \mathrm{a}\left(\delta_{\mathrm{C}} 106.7\right)$; and from the methyl protons $20-\mathrm{H}_{3}\left(\delta_{\mathrm{H}} 1.28\right)$ to a carbonyl carbons C-1 $\left(\delta_{\mathrm{C}} 194.9\right), \mathrm{C}-4 \mathrm{a}$ and C-9b revealed a trimethylcyclohexenone ring (Figure $1 \mathrm{~b}$ ).

The long-range couplings from the methyl protons $12-\mathrm{H}_{3}\left(\delta_{\mathrm{H}} 1.45\right)$ to an oxygenated quaternary carbon $\mathrm{C}-5 \mathrm{a}\left(\delta_{\mathrm{C}} 80.3\right)$, an oxygenated olefinic carbon C-6 $\left(\delta_{\mathrm{C}} 162.5\right)$ and a methine carbon C-9a $\left(\delta_{\mathrm{C}} 54.1\right)$;
Table $1{ }^{13} \mathrm{C}$ - and ${ }^{1} \mathrm{H}-\mathrm{NMR}$ data for 1

\begin{tabular}{|c|c|c|}
\hline Position & $\delta_{C}$ & $\delta_{H}($ multiplicity, $\mathrm{J}$ in $\mathrm{Hz}$ ) \\
\hline 1 & 194.9 & \\
\hline 2 & 125.6 & $5.64(\mathrm{br} \mathrm{s})$ \\
\hline 3 & 161.6 & \\
\hline 4 & 76.9 & \\
\hline $4 a$ & 106.7 & \\
\hline $5 a$ & 80.3 & \\
\hline 6 & 162.5 & \\
\hline 7 & 111.9 & \\
\hline 8 & 190.9 & \\
\hline 9 & 100.4 & \\
\hline $9 a$ & 54.1 & $3.65(\mathrm{~s})$ \\
\hline $9 b$ & 59.6 & \\
\hline 10 & 18.2 & $2.01(d, 1.0)$ \\
\hline 11 & 24.4 & $1.36(\mathrm{~s})$ \\
\hline 12 & 25.8 & $1.45(\mathrm{~s})$ \\
\hline 13 & 6.8 & $1.63(\mathrm{~s})$ \\
\hline 14 & 170.8 & \\
\hline 15 & 120.2 & $6.38(d, 15.0)$ \\
\hline 16 & 139.6 & $7.30(\mathrm{dd}, 15.0,11.0)$ \\
\hline 17 & 131.1 & $6.28(\mathrm{ddd}, 15.0,11.0,1.0)$ \\
\hline 18 & 137.4 & $6.11(\mathrm{dq}, 15.0,7.0)$ \\
\hline 19 & 18.78 & $1.87(\mathrm{dd}, 7.0,1.0)$ \\
\hline 20 & 18.80 & $1.28(\mathrm{~s})$ \\
\hline $14-\mathrm{OH}$ & & $16.43(\mathrm{~s})$ \\
\hline
\end{tabular}

NMR spectra were taken on a Varian NMR System 500 NB CL (Varian, Palo Alto, CA, USA) in chloroform- $d$ with the residual solvent peak as an internal standard $\left(\delta_{\mathrm{C}} 77.0, \delta_{\mathrm{H}} 7.26 \mathrm{ppm}\right)$.

from the methyl protons $13-\mathrm{H}_{3}\left(\delta_{\mathrm{H}} 1.63\right)$ to C-6, an olefinic carbon C-7 $\left(\delta_{\mathrm{C}} 111.9\right)$ and a carbonyl carbon C-8 $\left(\delta_{\mathrm{C}} 190.9\right)$; and from $9 \mathrm{a}-\mathrm{H}$ $\left(\delta_{\mathrm{H}} 3.65\right)$ to $\mathrm{C}-5 \mathrm{a}, \mathrm{C}-6, \mathrm{C}-8$ and an olefinic carbon C-9 $\left(\delta_{\mathrm{C}} 100.4\right)$ established dimethylcyclohexenone ring. In addition, a hydrogenbonded hydroxyl proton $14-\mathrm{OH}\left(\delta_{\mathrm{H}} 16.43\right)$ long-range coupled with three olefinic carbons C-9, C-14 $\left(\delta_{\mathrm{C}} 170.8\right)$ and C-15 $\left(\delta_{\mathrm{C}} 120.2\right)$ and a sequence from an olefinic proton $15-\mathrm{H}\left(\delta_{\mathrm{H}}\right.$ 6.38) to the methyl protons $19-\mathrm{H}_{3}\left(\delta_{\mathrm{H}} 1.87\right)$ through three olefinic protons $16-\mathrm{H}\left(\delta_{\mathrm{H}}\right.$ $7.30), 17-\mathrm{H}\left(\delta_{\mathrm{H}} 6.28\right)$ and $18-\mathrm{H}\left(\delta_{\mathrm{H}} 6.11\right)$ determined the hydroxyhexatriene side chain to connect at C-9 of the dimethylcyclohexenone ring. The stereochemistry of the olefins at C-15 and C-17 was determined as trans by their coupling constants $(J=15.0 \mathrm{~Hz})$. Finally, long-range couplings from the methine protons $9 \mathrm{a}-\mathrm{H}$ to $\mathrm{C}-1$, C-9b and C-20 $\left(\delta_{\mathrm{C}} 18.80\right)$ and from $20-\mathrm{H}_{3}$ to C-9a elucidated the connectivity between the two cyclohexenone rings. Thus, the planar structure of $\mathbf{1}$ was determined as shown in Figure la.

The relative configuration was assigned on the basis of the analysis of NOE spectra. The NOE (Figure 1c) between $2-\mathrm{H}$ and $13-\mathrm{H}_{3}$, between $9 \mathrm{a}-\mathrm{H}$ and $12-\mathrm{H}_{3}$, between $9 \mathrm{a}-\mathrm{H}$ and $20-\mathrm{H}_{3}$ and between $12-\mathrm{H}_{3}$ and $20-\mathrm{H}_{3}$ indicated that the hydroxyl groups at $\mathrm{C}-4 \mathrm{a}$, the hydrogen atom $9 \mathrm{a}-\mathrm{H}$ and the two methyl groups $\mathrm{C}-12$ and C-20 showed the same direction on the furan ring as shown in Figure 1c.

We herein isolated a new sorbicillin derivative together with three known dimeric sorbicillin derivatives. Some homodimeric analogs of sorbicillin, such as bisorbibutenolide, ${ }^{10}$ bisvertinolone ${ }^{11}$ and trichodimerol, ${ }^{12}$ which were isolated from fungi Penicillium spp., Trichoderma spp. or Verticillium spp., have been reported. On the other hand, only two sorbicillin derivatives, that is, sorbicillactones A and B, have been reported as heterodimeric compounds that consist of sorbicillin and 
alanine fumaramide units as secondary metabolites of marine spongederived fungus $P$. chrysogenum. ${ }^{15}$ The new sorbicillinoid, $\mathbf{1}$, may be produced by cyclization between sorbicillin and the trihydroxyquinol antibiotic, KS $506 \mathrm{p},{ }^{16}$ as precursors.

It has been reported that sorbicillin derivatives are radical scavengers. ${ }^{16}$ Therefore, to evaluate the activity of $\mathbf{1}$ as a radical scavenger, we examined its inhibitory effect on L-glutamate toxicity in neuronal hybridoma N18-RE-105 cells, which can assess the radical scavenging activity. ${ }^{17-20}$ The protective activity of $\mathbf{1}$, bisorbibutenolide, bisvertinolone and trichodimerol against L-glutamate toxicity in N18-RE-105 cells was tested. Compound 1, bisorbibutenolide and bisvertinolone reduced L-glutamate toxicity in N18-RE-105 cells with $\mathrm{EC}_{50}$ values of 71,61 and $49 \mu \mathrm{M}$, respectively; however, trichodimerol showed weak activity $\left(\mathrm{EC}_{50}>100 \mu \mathrm{M}\right)$.

\section{ACKNOWLEDGEMENTS}

This work was supported by a grant from the New Energy and Industrial Technology Department Organization (NEDO) of Japan and a Grant-in-Aid for Scientific Research (20380070 to KS) from The Japan Society for the Promotion of Science (JSPS), The Ministry of Education, Culture, Sports, Science and Technology (MEXT).

1 Blunt, J. W. et al. Marine natural products. Nat. Prod. Rep. 26, 170-244 (2009).

2 Molinski, T. F., Dalisay, D. S., Lievens, S. L. \& Saludes, J. P. Drug development from marine natural products. Nat. Rev. Drug Discov. 8, 69-85 (2009).

3 Wagner-Döbler, I., Beil, W., Lang, S., Meiners, M. \& Laatsch, H. Integrated approach to explore the potential of marine microorganisms for the production of bioactive metabolites. Adv. Biochem. Eng. Biotechnol. 74, 208-238 (2002).

4 Blunt, J. W. et al. Marine natural products. Nat. Prod. Rep. 26, 170-244 (2009).

5 Saleem, M. et al. Marine natural products of fungal origin. Nat. Prod. Rep. 24, 1142-1152 (2007).
6 Motohashi, K. et al. New sesquiterpenes, JBIR-27 and -28 , isolated from a tunicate-derived fungus, Penicillium sp. SS080624SCf1. J. Antibiot. 62, 247-250 (2009).

7 Motohashi, K., Inaba, S., Takagi, M. \& Shin-ya, K. JBIR-15, a new aspochracin derivative, isolated from a sponge-derived fungus, Aspergillus sclerotiorum Huber Sp080903f04. Biosci. Biotechnol. Biochem. 73, 1898-1900 (2009).

8 Izumikawa, M. et al. JBIR-37 and -38, novel glycosyl benzenediols, isolated from the sponge-derived fungus, Acremonium sp. SpF080624G1f01. Biosci. Biotechnol. Biochem. 73, 2138-2140 (2009).

9 Zhang, D. H. et al. Redoxcitrinin, a biogenetic precursor of citrinin from marine isolate of fungus Penicillium sp. J. Microbiol. Biotechnol. 17, 865-867 (2007).

10 Abe, N., Murata, T. \& Hirota, A. Novel oxidized sorbicillin dimers with 1,1-diphenyl-2picrylhydrazyl-radical scavenging activity from a fungus. Biosci. Biotechnol. Biochem. 62, 2120-2126 (1998).

11 Trifonov, L. S. et al. Bisvertinols-a new group of dimeric vertinoids from Verticillium intertextum. Tetrahedron 42, 3157-3179 (1986).

12 Andrade, R., Ayer, W. A. \& Mebe, P. P. The metabolites of Trichoderma Iongibrachiatum. 1. Isolation of the metabolites and the structure of trichodimerol. Can. J. Chem. 70, 2526-2535 (1992).

13 Sassa, T., Aoki, H., Namiki, M. \& Munakata, K. Plant growth promoting metabolites of Sclerotinia scletotiorum part I. Isolation and structures of sclerotinin A and B. Agric. Biol. Chem. 32, 1432-1439 (1968).

14 Furihata, K. \& Seto, H. Constant time HMBC (CT-HMBC), a new HMBC technique useful for improving separation of cross peaks. Tetrahedron Lett. 39, 7337-7340 (1998).

15 Bringmann, G. et al. The first sorbicillinoid alkaloids, the antileukemic sorbicillactones $\mathrm{A}$ and $\mathrm{B}$, from a sponge-derived Penicillium chrysogenum strain. Tetrahedron 61, 7252-7265 (2005).

16 Hirota, A., Morimitsu, Y. \& Hojo, H. New antioxidative indophenol-reducing phenol compounds isolated from the Mortierella sp. fungus. Biosci. Biotechnol. Biochem. 61, 647-650 (1997).

$17 \mathrm{Kim}$, W. G. et al. New diphenazines with neuronal cell protecting activity, phenazostatins A and B, produced by Streptomyces sp. J. Antibiot. 50, 715-721 (1997).

18 Murakami, Y. et al. Formobactin, a novel free radical scavenging and neuronal cell protecting substance from Nocardia sp. J. Antibiot. 49, 839-845 (1996).

19 Shin-ya, K. et al. Carquinostatin B, a new neuronal cell-protecting substance produced by Streptomyces exfoliatus. Biosci. Biotechnol. Biochem. 61, 1768-1769 (1997).

20 Shin-ya, K., Shimizu, S., Kunigami, T., Furihata, K. \& Seto, H. A new neuronal cell protecting substance, lavanduquinocin, produced by Streptomyces viridochromogenes. J. Antibiot. 48, 574-578 (1995). 